\title{
Simulação Paramétrica de um icosaedro pantográfico no Grasshopper, baseado em patentes de Hoberman
}

\author{
Parametric simulation of a scissor-like icosahedron in Grasshopper, based on Hoberman patent
}

\author{
- Maurício Guimarães de Oliveira \\ Universidade Estadual de Campinas - \\ UNICAMP, Brasil \\ oliveiramauricio@gmail.com \\ - Ana Lúcia Nogueira de Camargo Harris \\ Universidade Estadual de Campinas - \\ UNICAMP, Brasil \\ luharris2011@gmail.com
}

\begin{abstract}
This article proposes the creation of a virtual icosahedric parametric structure based on Chuck Hoberman's patent "Reversibly expandable doubly-curved truss structure", which contains the single-angulated bar. It was used the software Rhinoceros with Grasshopper parametric plugin to develop the simulation, elucidating it's potential to develop and study complex geometries.
\end{abstract}

Keywords: Simulation, Scissor-like, Hoberman, Grasshopper, Icosahedron

\section{Introdução}

Desde a invenção do pantógrafo por Scheiner no séc. XVII, muito se produziu em decorrência da compreensão de sua geometria articulada transformável. Mais do que apenas reproduzir ou ampliar gravuras, as aplicações de seu sistema em estruturas na escala de edifícios propiciou a criação de um novo campo de estudos na arquitetura: as estruturas dinâmicas articuladas.

Apesar da existência de renomados pesquisadores no exterior, poucos se dedicaram a exploração destas soluções dinâmicas e articuladas resultando numa escassez de patentes nacionais ou registros de aplicações quaisquer. Podem ser citados como exemplos os simbólicos cinco anéis dos jogos de Sochii na Rússia em 2014 ou a cobertura dinâmica do estádio de Wimbledon. Como outro exemplo pode-se citar também a cobertura do pavilhão Quadracci do Museu de Arte de Milwalkee, idealizado pelo arquiteto Santiago Calatrava.

Este artigo aborda uma investigação sobre duas das patentes de Chuck Hoberman: Reversibly expandable doublycurved truss structure e Radial expansion/retraction truss structures, que trazem em seu conteúdo a single-angulated bar - uma inovação que permitiu a criação de novas estruturas pantográficas de forma mais simples, por se desenvolverem em apenas um plano cartesiano. A partir da compreensão desta, foi utilizado o software Rhinoceros/Grasshopper para criar um icosaedro pantográfico paramétrico, integralmente baseado na single-angulated bar, para aplicação de seu mecanismo e verificação de suas possibilidades.

\section{Procedimentos Metodológicos}

A estratégia adotada para o desenvolvimento desta pesquisa foi a simulação. No site dictionary.com, simulação é definida como a "representação do comportamento ou características de um sistema através de outro sistema, especialmente um software criado para este propósito". Então, neste artigo será demonstrado o funcionamento geométrico de um icosaedro pantográfico a partir de sua simulação virtual.

Porém, para que seja possível o simular, se faz necessário compreender historicamente os sistemas de articulação pantográfica que nos permitirá compreender seu funcionamento, incorporando a descrição geométrica de seus princípios matemáticos, conduzindo-nos a novas abstrações.

\section{Do pantógrafo a Emílio Perez Piñero}

O pantógrafo foi criado pelo matemático e astrônomo alemão Christopher Scheiner - que teria sonhado com um instrumento capaz de realizar cópias (SCHEINER, 2010) - após sua criação, teria continuado a sofisticá-lo para aprimorar seu funcionamento, publicando-o pela primeira vez em seu livro Pantographice em 1631. Seu funcionamento se baseia fundamentalmente no conceito de semelhança de triângulos e a razão de sua ampliação ou redução se dá pelo 
princípio de homotetia (LIMA, 1991). As relações entre estes conceitos aplicados ao pantógrafo podem ser unificadas e compreendidas através de um teorema elementar da geometria, conhecido como segundo teorema de Tales de Mileto. A partir da invenção do pantógrafo e da plena compreensão de sua geometria, suas propriedades puderam ser aplicadas a outros dispositivos além da ilustração e escultura, dando início a vasta aplicação em campos da arquitetura e a mecânica, permitindo sua sofisticação.

Em abril de 1859, o inventor americano L. K. Selden (1859) patenteou um novo tipo de guarda-chuva (ou guarda-sol) cuja expansão e retração ocorrem através de barras articuladas pantográficas. Diferentemente do pantógrafo de Scheiner, as articulações necessárias para os movimentos de expansão e retração de seu guarda-chuva precisavam compor um sistema pantográfico cuja transformação ocorresse de forma radial, utilizando diversas barras pantográficas unidas por eixos, sendo que estes funcionavam como raios direcionados ao mesmo centro de circunferência. Ou seja, conforme o guardachuva fosse aberto, sua circunferência aumentaria mantendo o mesmo centro - com uma inevitável variação em sua posição vertical, (eixo Z) por utilizar de barras pantográficas retilíneas. Isso ocorre porque ao trabalhar com articulações cujos eixos centrais estejam deslocados do centro geométrico da barra, estas articulações desenvolverão arcos entre si cujo ângulo é variável. O desenvolvimento de articulações arqueadas com ângulo fixo viriam apenas 140 anos depois, com a singleangulated bar, por Hoberman.

\section{Chuck Hoberman e a single-angulated bar}

O engenheiro norte-americano Chuck Hoberman registrou em 1990 a patente de uma estrutura treliçada expansível e reversível de dupla curvatura (HOBERMAN apud ANAF e HARRIS, 2014), na qual a principal inovação presente nesta foi a criação da single-angulated bar. Hoberman, ao invés de utilizar as tradicionais barras pantográficas retilíneas, criou novas estruturas a partir de barras anguladas, ou seja, formadas por duas semi-retas convergentes e não paralelas, utilizando de uma articulação na intersecção das semi-retas, cuja forma é análoga a um acento circunflexo. A vantagem de sua utilização se deu por "possibilitar, pela primeira vez a uma estrutura pantográfica, a transformação destas articulações restritas a planos radiais de expansão sem variação angular, ou seja, restrita a dois eixos cartesianos" (OLIVEIRA e HARRIS, 2015) - diferentemente das criações anteriores, como na criação das estruturas tridimensionais e reticulares de Piñero (1965) nas quais as expansões radiais ampliam o ângulo de curvatura da estrutura ou, para impedir de fazê-lo, operem transformações em três eixos cartesianos, como no guardachuva de Selden.

Ao se utilizar de duas single-angulated bar, sendo a segunda barra simetricamente espelhada, torna-se possível criar um par de barras que funcionam como uma articulação pantográfica (figura 1), porém com expansão radial e cujo ângulo é constante. Ciente da estabilidade angular desse conjunto "é possível então concluir que qualquer aresta ou arco que componha um poliedro pode ser substituído por, pelo menos, um par de barras de ângulo único, conforme figura 2 (OLIVEIRA e HARRIS, 2015).

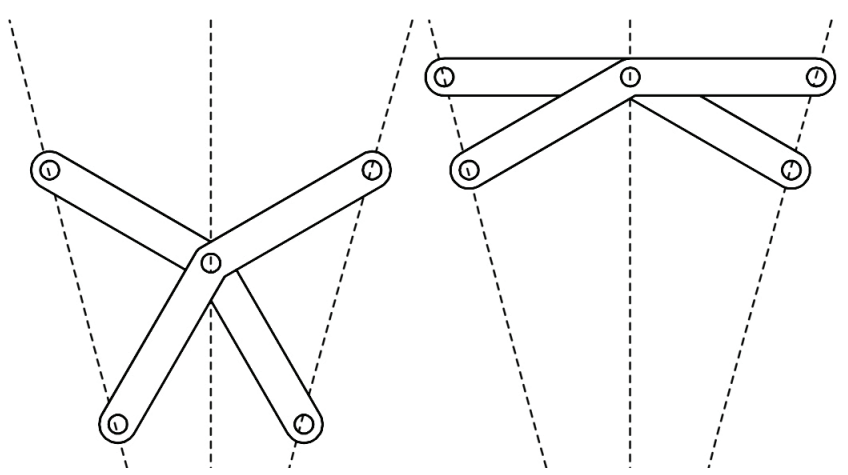

Figura 1: Desenvolvimento das single-angulated bars.

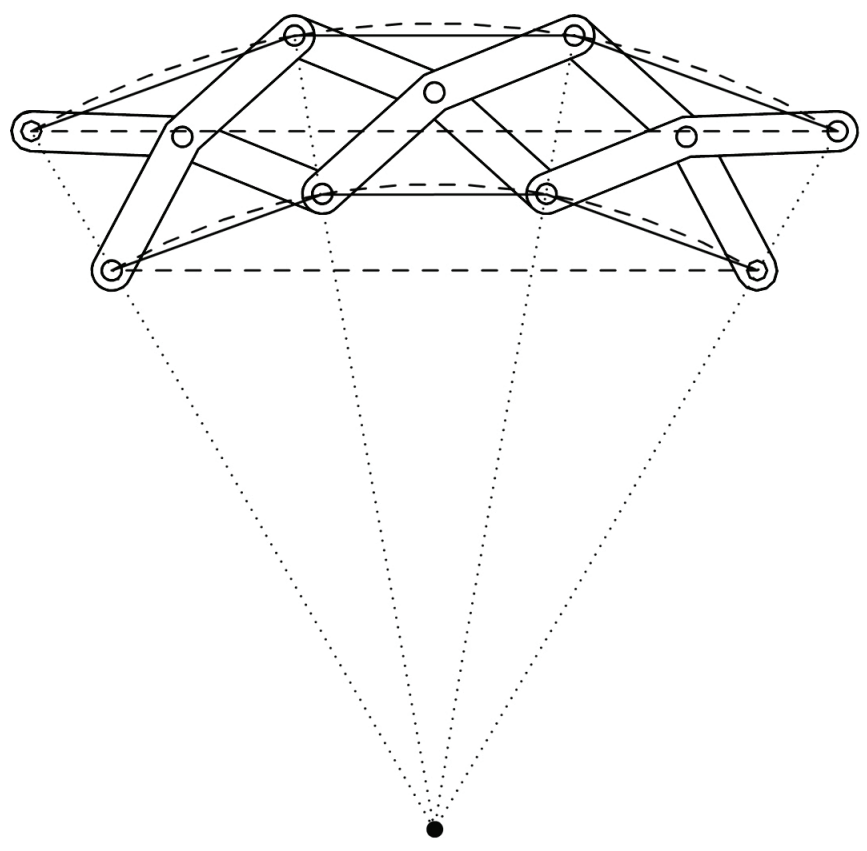

Figura 2: Arestas e arcos em tracejados, e sua possível substituição por três pares de single-angulated bars.

Com o conteúdo de seu funcionamento compreendido, foi desenvolvida uma simulação no software Rhinoceros facilitada pelo plugin Grasshopper, que permite a criação de algoritmos visuais a partir de raciocínio geométrico. Com ele foi possível recriar o sistema das single-angulated bars de Hoberman de forma paramétrica e, com elas, desenvolver o icosaedro pantográfico a partir da substituição de suas arestas pelas barras de Hoberman.

O próprio Hoberman utilizou deste princípio para criar poliedros expansíveis, sendo o mais famoso a esfera de Hoberman-criaçãoesta que o tornou conhecido mundialmente.

\section{Icosaedros}

O icosaedro é um poliedro de Platão que contém 20 faces - 
triângulos eqüiláteros - 30 arestas e 12 vértices, sendo cada vértice formado pela junção de cinco arestas. Exatamente como os demais poliedros de Platão, o icosaedro está perfeitamente contido dentro de uma esfera na qual todos os vértices tocam sua superfície.

O icosaedro pode ser construído a partir de três retângulos áureos perpendiculares entre si: sendo cada um coincidente com um dos três planos cartesianos (figura 3). Então, a conexão de cada vértice dos retângulos com os cinco vértices mais próximos resulta na construção de um icosaedro. Pela sua facilidade de construção este será o processo adotado no desenvolvimento da simulação geométrica.

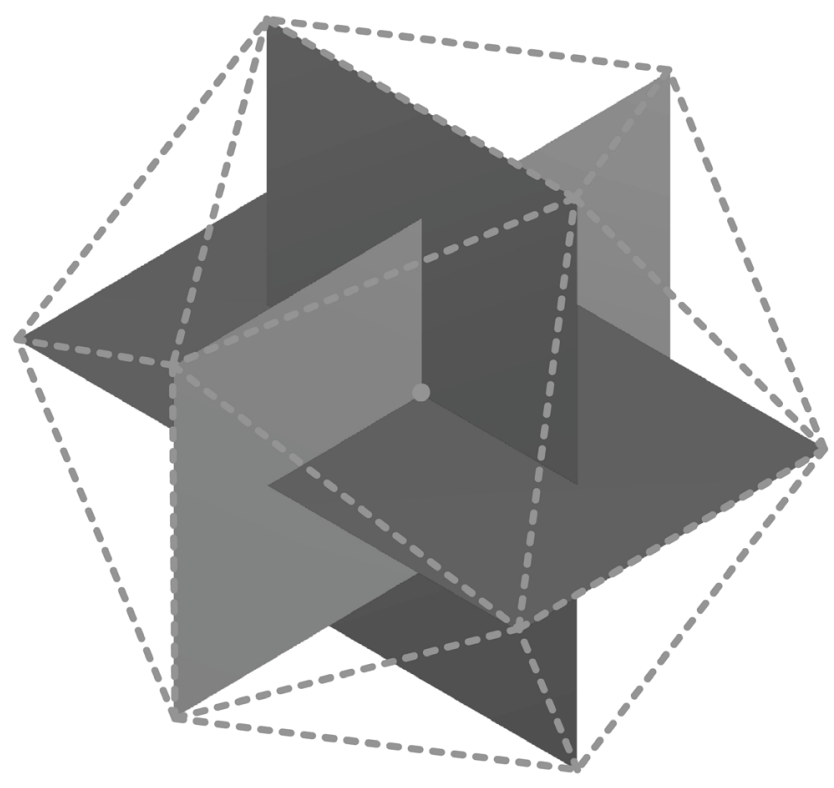

Figura 3: Icosaedro obtido pelos vértices de três retângulos áureos, sendo o ponto seu centro geométrico.

Todas suas faces geram um tetraedro irregular idêntico, cuja altura é perfeitamente coincidente com o centro geométrico do icosaedro, conforme ilustrado pela figura 4.

\section{Descrição do processo}

A construção no Grasshopper se inicia pela confecção de um retângulo áureo utilizando do componente Golden ratio, o qual traz a razão áurea - teta - internalizada. As menores arestas deste retângulo são coincidentes com as arestas dos triângulos eqüiláteros que comporão o icosaedro e, assim, o desenvolvimento se iniciará por uma destas, como na fig.5a. 0 centro geométrico do retângulo também será coincidente com o centro geométrico do icosaedro, sendo este imprescindível para o desenvolvimento da simulação.

Para a criação do arco que dará origem ao sistema pantográfico em substituição à aresta do poliedro serão utilizados os dois vértices da menor aresta do retângulo áureo e um terceiro ponto também eqüidistante de seu centro geométrico (raio da circunferência/esfera), conseguido pela translação do ponto central ao longo do eixo cartesiano Y utilizando a referida distância (fig.5a). Este arco oriundo dos três pontos deverá ser dividido em $\mathrm{X}$ partes (paramétrico) devendo sua variação ser impreterivelmente um número par, para que os conjuntos de barras anguladas estejam conectados sempre pelas extremidades, nunca pelo meio.

Após realizar essa divisão, os três primeiros pontos deverão gerar linhas cujo início se dará no centro geométrico do retângulo áureo (fig.5b). Na linha do meio deverá ser utilizado o componente evaluate curve do Grasshopper, para criar um ponto deslizante ao longo desta reta. Este ponto será responsável por transladar os eixos articulados pantográficos.

A distância entre o ponto localizado na extremidade da reta do meio e o mesmo ponto nas retas laterais será utilizada como raio de uma nova circunferência a ser criada, cujo centro deverá estar vinculado ao ponto deslizante, deslocando-a consigo. Então, deverão ser encontrados os pontos resultantes das intersecções entreas duas retas externas e a circunferência (fig.6a), pois estes serão utilizados para criação do primeiro par de barras anguladas. É necessário selecionar um ponto mais próximo do centro do retângulo na primeira linha e, então, o ponto mais afastado do centro na linha oposta, podendo-se gerar uma polyline que funcionará como a primeira barra e a espelhar através da reta central, utilizando de um plano que atuará como um eixo de simetria (fig.6b).
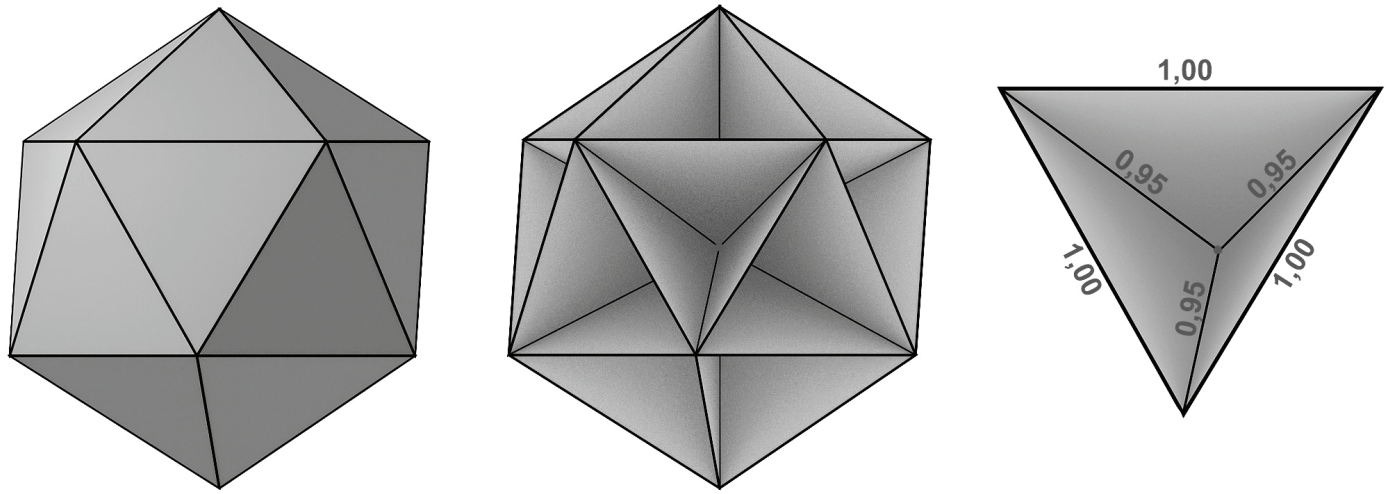

Figura 4: Icosaedro, sua composição por diversos tetraedros iguais, e as proporções de cada aresta. 

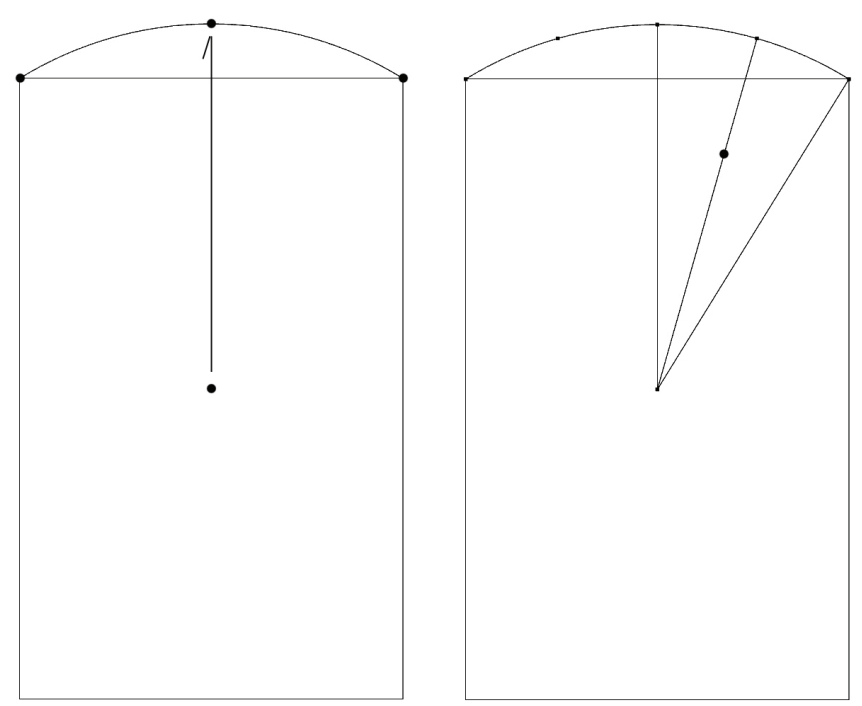

Figura 5: Retângulo áureo e arco representando a aresta do icosaedro e seu centro geométrico já contendo as divisões no arco.
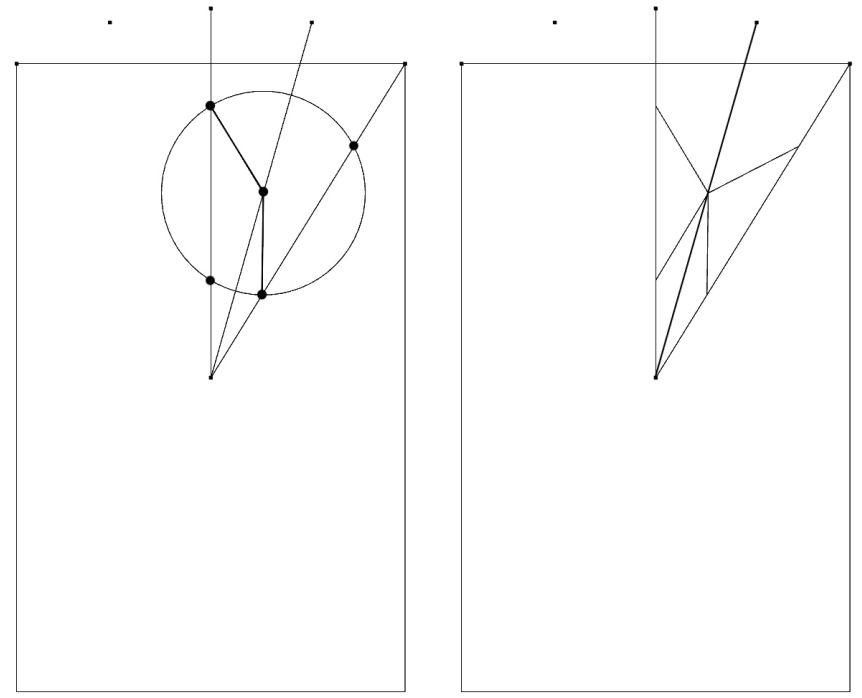

Figura 6: Intersecções entre a circunferência e as linhas externas gerando uma single-angulated bar e seu espelhamento gerando um par de barras.

Então, o primeiro par de barras deverá ser multiplicado utilizando o componente array polar, que permitirá a criação de cópias do primeiro par de barras com determinada variação angular (fig.7a). Para que o modelo seja perfeitamente paramétrico é necessário utilizar o mesmo valor definido para a divisão do primeiro arco, porém dividido por dois - razão pela qual a já citada divisão do arco deve ser par. Isso fará com que todas as cópias sempre preencham integralmente a curvatura do arco. Assim como a variação angular solicitada pelo componente array polar deverá ser extraída do mesmo arco, para que sejam compatíveis. É importante nesta etapa verificar a variação tanto da quantidade de divisões do arco como sua expansão, alterando o valor definido para o componente evaluate curve já utilizado no passo anterior (fig.7b).
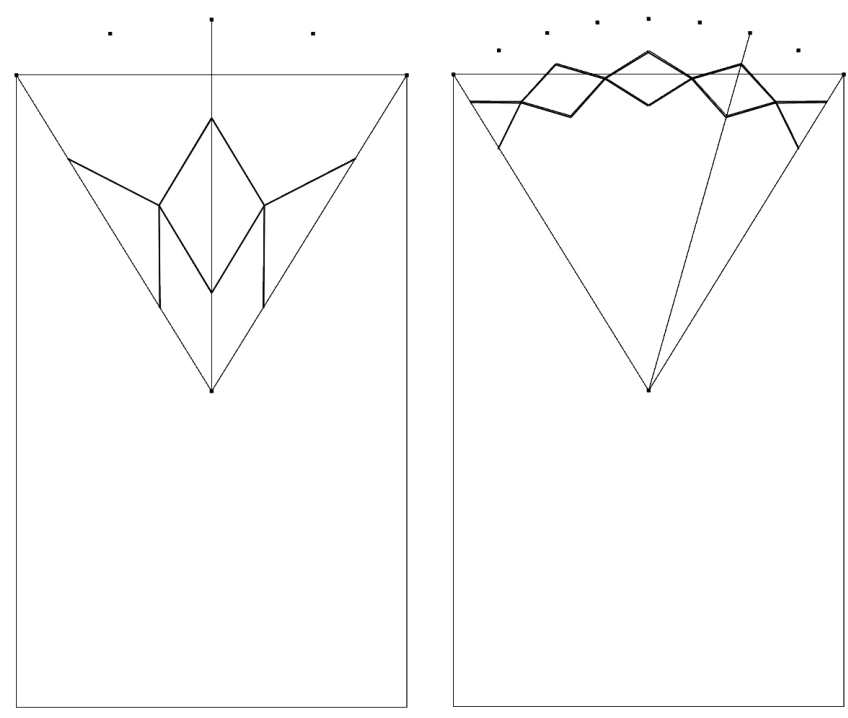

Figura 7: Conjunto de barras anguladas em substituição a aresta do icosaedro e alteração na quantidade de elementos e sua expansão.

A aresta pantográfica original - a primeira - deverá então ser rotacionada através de uma das linhas mais externas como ilustra a figura 8, num ângulo de precisamente setenta e dois graus - por ser um quinto de uma circunferência - gerando uma aresta que vamos chamar de segunda. A seguir, deve-se efetuar uma nova rotação utilizando o mesmo eixo e o mesmo ângulo, mas baseada na segunda aresta para a criação do que chamaremos de terceira aresta. Por último, será necessário repetir mais uma vez uma nova rotação com os mesmos parâmetros a partir da terceira aresta para criação da quarta e última aresta criada individualmente.

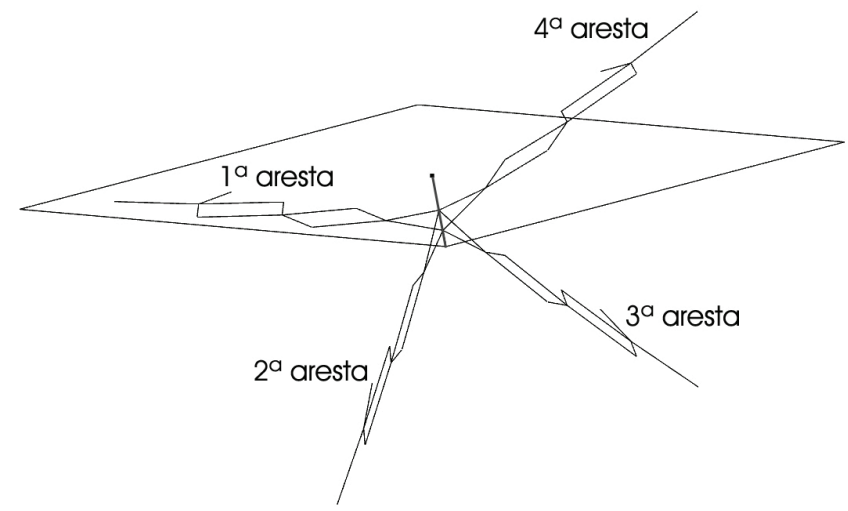

Figura 8: A linha a ser utilizada como eixo de rotação e todas as suas quatro cópias - arestas.

Com as quatro arestas finalizadas, e adotando a reta mais externa oposta àquela utilizada no passo anterior como eixo de rotação, será necessário empregar um segundo array polar com as geometrias pantográficas da primeira e segunda aresta para geração de cinco cópias - em analogia a cinco arestas do 
icosaedro - que resultarão no primeiro vértice completo e também do que chamaremos de cúpula (fig.9).

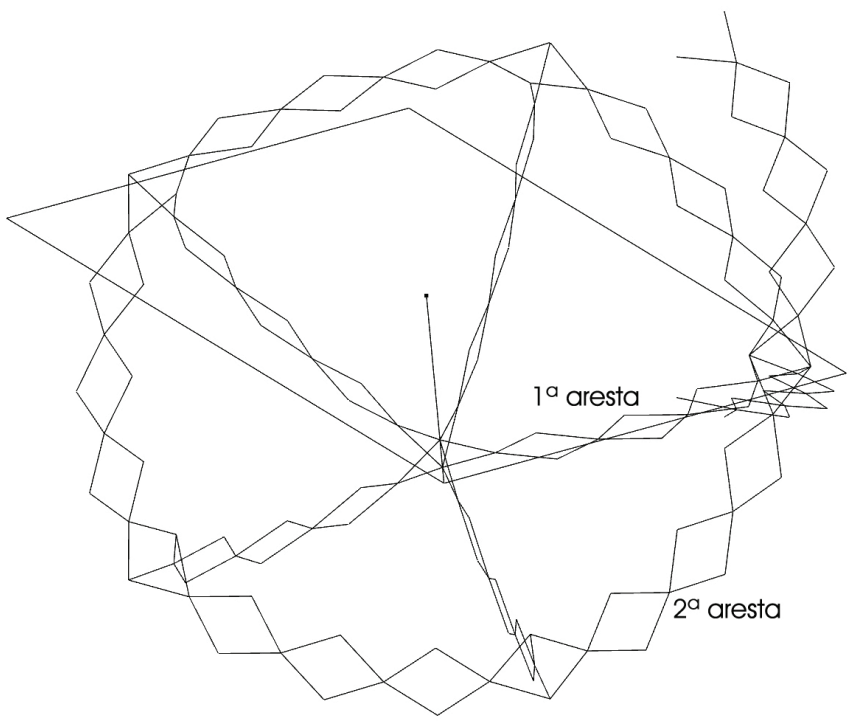

Figura 9: Cúpula resultante de cinco cópias da $1^{\mathrm{a}}$ e $2^{\mathrm{a}}$ arestas.

Através do mesmo eixo de rotação, porém utilizando das geometrias pantográficas da terceira e quarta arestas originais, um novo array polar com cinco cópias completará toda a porção central do icosaedro (fig.10).

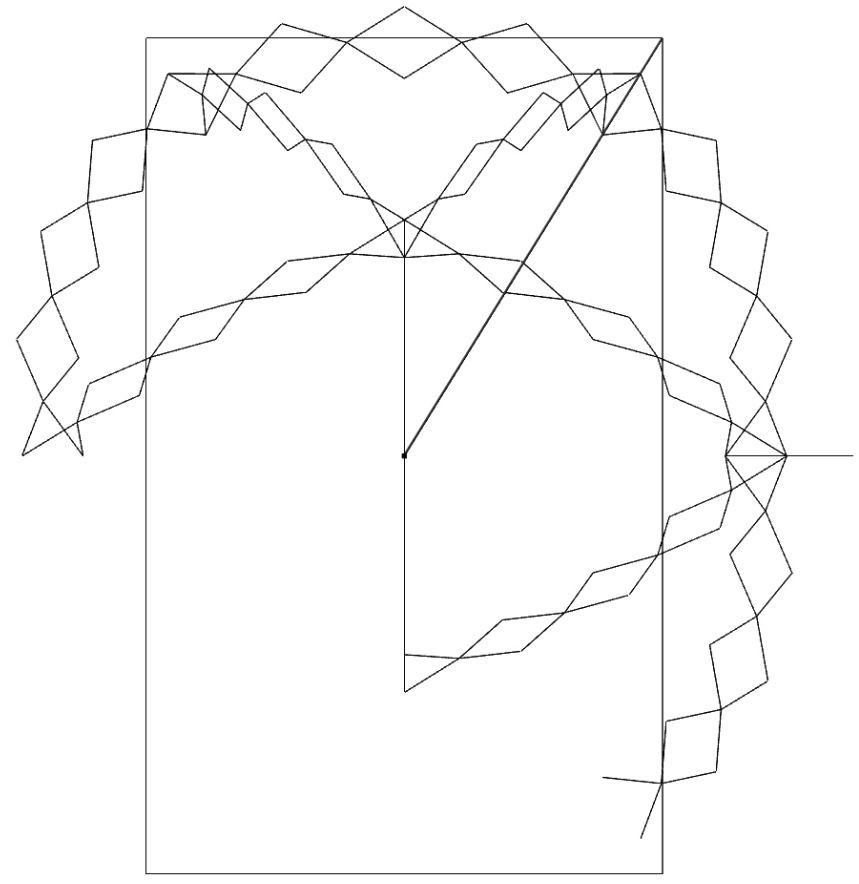

Figura 10: Articulações pantográficas da cúpula e porção central. perpendicular ao plano do retângulo. A rotação deverá descrever um ângulo de precisamente cento e oitenta graus para que a nova cúpula se encontre perfeitamente oposta à original (fig.11).

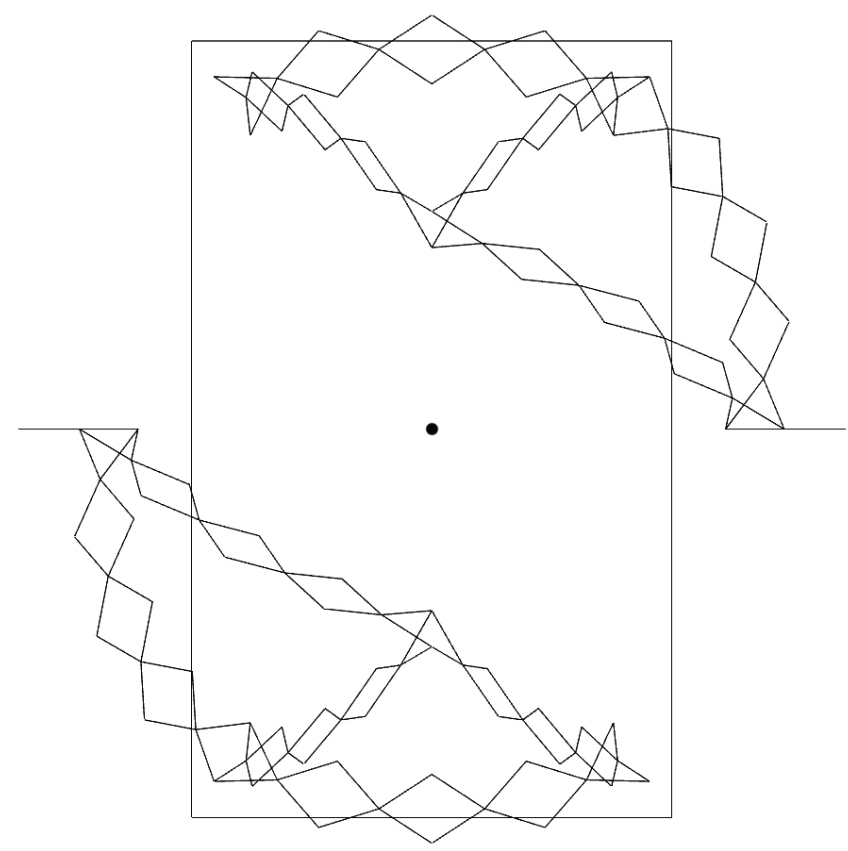

Figura 11: As duas cúpulas pantográficas nas extremidades do icosaedro.

Ao reativar a visualização de todos os componentes array polar, o icosaedro pantográfico estará pronto e articulando de forma síncrona todas as suas arestas (fig.12 e 13).

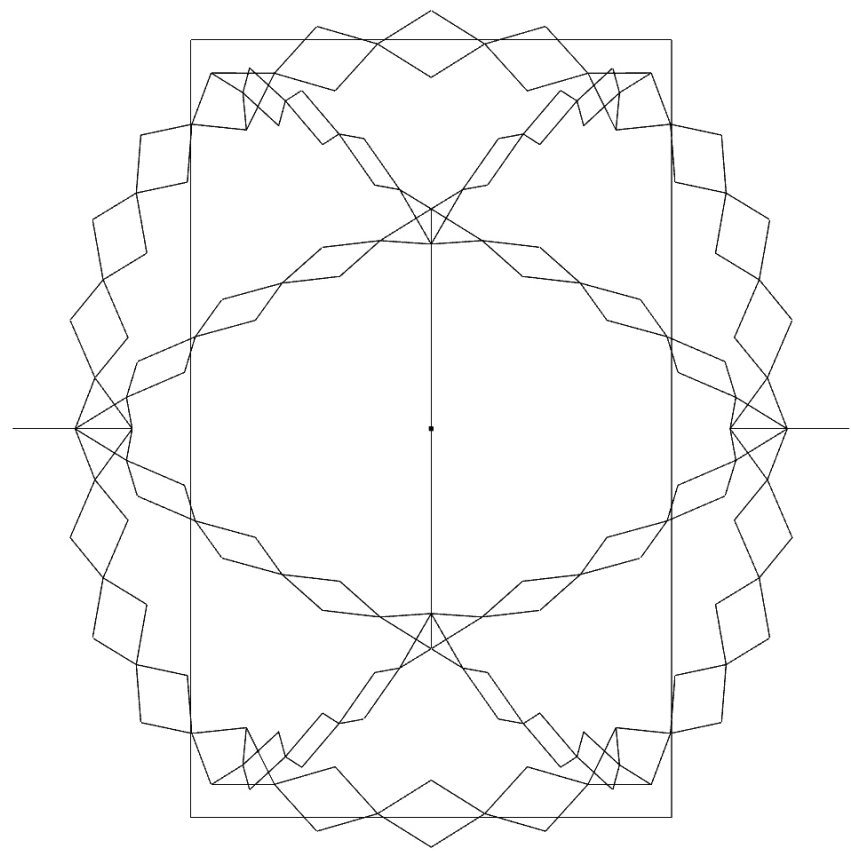

Figura 12: Todas as arestas pantográficas do icosaedro. 

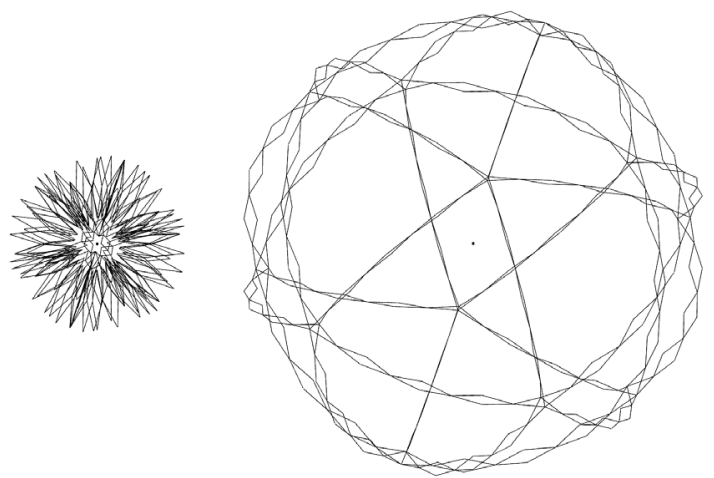

Figura 13: O icosaedro pantográfico totalmente retraído e expandido.

Para aprimoramento da visualização, numa etapa anterior, quando da criação da polyline para dar origem a um par de barras anguladas, pode-se sofisticar seu resultado criando superfícies para substituir as polylines, permitindo um resultado exeqüível por equipamentos de fabricação digital (fig.14).
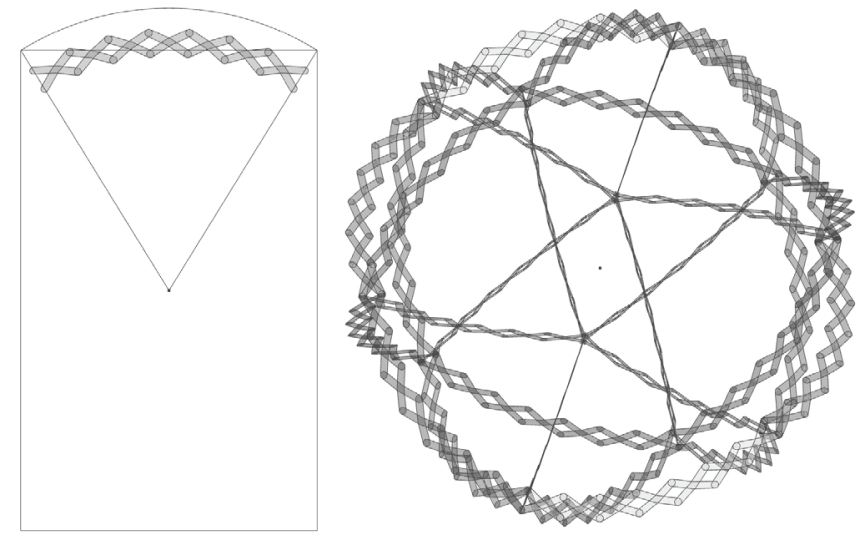

Figura 14: Icosaedro pantográfico composto por superfícies em substituição às polylines.

\section{Resultados}

Neste artigo foi descrita a construção paramétrica de um icosaedro dinâmico no Grasshopper, cujas arestas foram substituídas por articulações pantográficas, permitindo assim sua retração e expansão virtuais em perfeita analogia de desenvolvimento real, físico. O Grasshopper se mostrou uma ferramenta plena de simulação geométrica sem a ocorrência de quaisquer erros em sua programação. Logo, tornou-se perfeitamente possível estudar e criar o referido sólido geométrico, assim como outros novos poderão ser simulados e criados.

\section{Discussão}

O artigo esmiúça o funcionamento da single-angulated bar de Hoberman para a criação de um icosaedro pantográfico.
A compreensão de seu funcionamento evidencia sua simplicidade e as possibilidades de aplicação para sistemas geométricos mais sofisticados, que podem ser utilizados para o desenvolvimento desde pequenos abrigos efêmeros a grandes domos geodésicos como os de Buckminster Fuller (1954), com grande vantagem por ter a sua logística facilitada em função de sua habilidade de expansão e retração facilidade esta experimentada por Emílio Perez Piñero pelo desenvolvimento de estruturas dinâmicas assumidamente baseadas na obra de Fuller. Além das aplicações citadas, uma vez que qualquer poliedro possa ser construído a partir de estruturas articuladas, a forma esférica não é uma limitação para o desenvolvimento de estruturas - apenas a escolhida para esmiuçar virtualmente neste artigo. Tendo em vista a inexistência de limitações na forma geométrica, evidenciase a potencialidade destes sistemas para exploração e desenvolvimento de novas formas em Arquitetura.

\section{Agradecimentos}

Gostaria de agradecer aos professores da Universidade Estadual de Campinas que tanto colaboraram com a produção deste artigo e com tamanha qualidade de ensino na pósgraduação. Também, à equipe do SIGraDi pela presteza e prontidão para auxiliar com as dúvidas relativas à publicação.

\section{Referências}

Anaf, M.; Harris, A. L. N. C. (2014). Transformable design: an approach between mathematics and arts. GEOMETRIAS 14 XIII Encontro da APROGED, 2014, 71-74.

BBC News. Sochi Olympics: Ring malfunctions at opening ceremony, disponível em: http://www.bbc.com/news/worldeurope-26093161

Fuller, B.: Building construction. Disponível em: https://www. google.com/patents/US2682235

Galilei, G.; Scheiner, C. (2010). On Sunspots Translated and Introduced by Eillen Reeves \& Albert Van Helden. Chicago: University of Chicago Press.

Hoberman, C. Reversibly expandable doubly-curved truss structure. Disponível em:

http://www.google.com/patents/US4942700

Hoberman, C. Radial expansion/retraction truss structures. Disponível em: http://www.google.com/patents/US5024031

Lima, E. L. (1991). Medida e Forma em geometria. Rio de Janeiro: Sociedade Brasileira de Matemática.

Milwaukee Art Museum. Pavilhão Quadracci. Disponível em: https://mam.org/info/details/quadracci.php

Oliveira, M. G.; Harris, A. L. N. C. (2015). Modelagem Paramétrica de um Domo: uma oportunidade para arquitetura dinâmica. XII Congreso Nacional de Profesores de Expresión Gráfica. No prelo.

Pinero, E. P.: Three dimensional reticular structure. Disponível em: http://www.google.com/patents/US3185164.

Selden, L. K.: Umbrella. Disponível em: https://www.google. com/patents/US23503. 